\title{
Implementation of BIM into cold-formed steel residential buildings
}

\author{
M. Abu-Hamd \\ Structural Engineering Department, Faculty of Engineering, \\ Cairo University, Egypt
}

\begin{abstract}
Cold-formed steel construction (CFS) has proven to be a worthy alternative to traditional building systems due to its high strength to weight ratio, high degree of dimensional exactness and sustainability. The information integration provided by Building Information Modelling (BIM) can be utilized to enhance the efficiency of this construction system. Programming tools specific to CFS residential buildings can be utilized during the different project phases to facilitate BIM implementation. The objective of this paper is to demonstrate how successful BIM implementation using tools developed for CFS residential buildings can be employed to develop an efficient CFS residential building system. The paper introduces three tools related to BIM uses in Programming, Design Authoring, Structural Analysis, and Digital Fabrication. During the planning phase, complex floor plan arrangements are easily created from few simple modules similar to modular construction. During the design phase, the building model is created from parametric CFS objects of walls, floors, and bracings. Structural optimization tools related to member and system optimization are also employed during the design stage. Once the building model has been created using these tools, it can be used efficiently to explore and evaluate the project's constructability before it is built, produce workshop drawings, visualize construction processes through 4D simulation and clash detection in addition to the required data for Numerical Control Machine fabrication.

Keywords: BIM, cold formed steel, industrialized building systems, structural optimization, parametric objects.
\end{abstract}




\section{Introduction}

The largest component of the world's building stock is, by far, residential structures. Demand for these structures is growing: according to the UN anticipated growth in the world's population from 2010 to 2050 is 1.4 billion with $97 \%$ occurring in the least developed regions, e.g. Africa and Asia. To meet such a challenge, it is necessary to explore the latest construction technologies, and to create innovative building systems that have the potential to bring highperformance affordable housing within reach of new markets. Among the available construction systems that satisfy the previous conditions, light (coldformed) steel (CFS) framing systems (Figure 1) have proven to be a worthy alternative to traditional systems. Potential advantages of such light steel framing systems include the high degree of dimensional exactness of the members, high strength-to-weight ratio of the members, high recycled content, ease of construction, and other proven efficiencies.

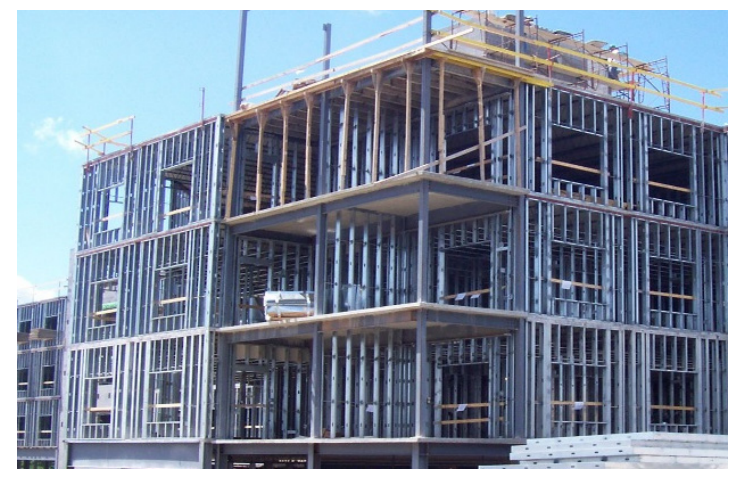

Figure 1: Cold-formed steel residential building.

The basic building elements of CFS systems are cold-formed C or U sections that are fabricated off-site into panels and then transported to site ready for erection. This construction system already lends itself to the application of industrialization techniques, such as lean and Just In Time (JIT) techniques, to enhance the performance of the construction industry [1].

Recent advances in the application of Building Information Modeling (BIM) into the Architecture-Engineering-Construction (AEC) industries present an additional mean to further enhance the efficiency of CFS projects. Review of available BIM implementation in CFS residential projects [2] concluded that CFS projects have not yet benefitted from the information integration provided by BIM implementation.

The objective of this paper is to demonstrate how successful BIM implementation using tools developed for CFS residential buildings can be employed to develop an efficient CFS residential building system. First a suitable BIM Execution Plan is prepared to ensure that all parties involved in the project are clearly aware of the opportunities and responsibilities associated with the 
incorporation of BIM into the project workflow. The "BIM Project Execution Planning Guide" [3] provides the following structured four-step procedure for creating and implementing BIM:

1. Identify the high value BIM Goals and Uses during project planning, design, construction and operational stages.

2. Design the BIM Execution Process.

3. Define the BIM deliverables in the form of Information Exchange.

4. Develop the infrastructure in the form of contracts, communication procedure, technology and quality control to support the implementation.

\section{BIM implementation into CFS residential projects}

The first step in the procedure is to identify the high value BIM Goals and Uses during project planning, design, construction and operational stages. The guide [3] identifies twenty-five BIM uses which are organized by project phases: planning, design, construction and operation. Out of these BIM uses, the following uses shall be employed to enhance the efficiency of CFS residential projects:

1. During Planning Phase: Programming

2. During Design Phase: Structural Analysis and Design Authoring

3. During Construction Phase: Digital Fabrication

\section{BIM use during planning phase: programming}

Programming, in BIM terminology [3], is a process in which a spatial program is used to assess design performance in regard to spatial requirements. The developed BIM model allows the project team to analyze space and understand the complexity of space standards and regulations. Critical decisions are made in this phase of design and bring the most value to the project when needs and options are discussed with the client and the best approach is analyzed.

A key issue in the building construction industry that prevents house building from achieving the production efficiency of other industries is the great variability in floor plan configurations. In order to increase the production efficiency of building construction, it has to be reformed as an industrialized process where offsite prefabrication and mass production is feasible.

As an example, study of the common floor plans used in mid-rise multi-family residential buildings reveals that they have the following common characteristics: 1. The floor plan has several apartments (4 or 6) distributed around a stair core.

2. Each apartment contains areas for living, bedrooms, and services such as kitchens and bathrooms.

These common characteristics can be utilized to industrialize residential building construction by decomposing each residential unit into few basic standard modules so that diverse mixed floor plans can be created from these few basic module. This technology is adapted from modular construction [4] where factorybuilt units are transported to site and used to assemble the entire building. This industrialization technique shall enable CFS building construction to benefit from 
the advantages of other industries; i.e. cheaper and faster production. Furthermore, off-site fabrication guarantees high quality control as well.

This industrialization technique can be employed in the planning stage so that the preliminary 3D model of any complex floor plan arrangement can be easily created from few basic modules. A typical example is shown in Figure 1. This floor plan involves six apartments with area $63 \mathrm{~m}^{2}$ in each floor of a six-story building, i.e. 24 housing unit per one building. This entire building can be created using only the following three basic simple modules:

1. Module (1) used for the living area space,

2. Module (2) used for the bedroom space,

3. Module (3) used for kitchen/bathroom space (two alternatives).

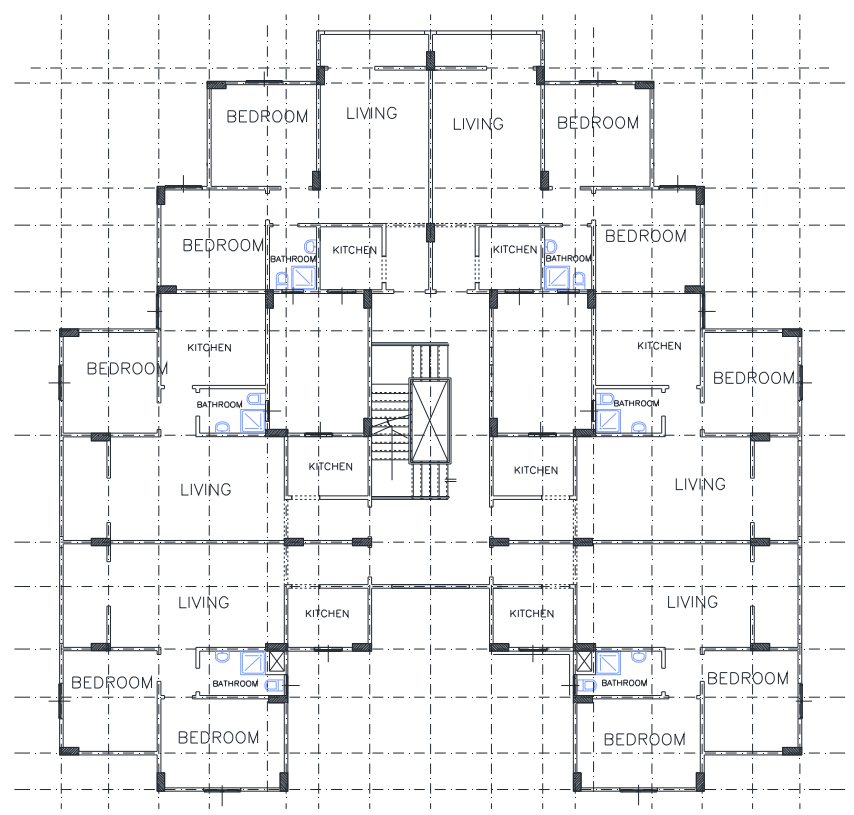

FLOOR PLAN CREATED FROM THREE BASIC MODULES

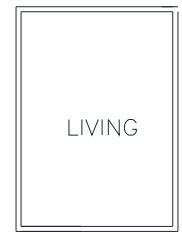

MODULE 1

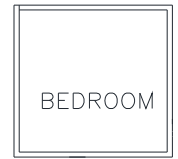

MODULE 2

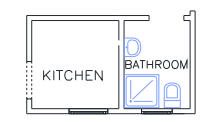

MODULE 3A

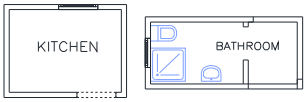

MODULE 3B

BASIC THREE MODULES USED IN FLOOR PLAN CREATION

Figure 2: Creation of complex floor plans from few basic modules. 


\section{BIM use during design phase: design authoring}

Design Authoring, in BIM terminology [3], is a process in which a design authoring software tool is used to develop a Building Information Model based on criteria that is important to the translation of the building's design. Design authoring tools are a first step towards BIM and the key is connecting the 3D model with a powerful database of properties, quantities, means and methods, costs and schedules.

In order to increase the productivity of the building construction industry, the integration of information within the project has to be handled in a more efficient way. Using BIM, the building is defined as a collection of interrelated objects that can be visualized in 3D. Building objects such as: walls, floors, roofs, windows, doors, etc. are tied to a database that contains all data related to the geometry, spatial relationships, geographic information, quantities, and properties of the building components. As such, the drawing becomes a model that is information rich and can readily be used to visualize the entire building lifecycle including the processes of construction and facility operation / maintenance. Such an accurate and intelligent model is useful throughout the entire life of the building. The parametric modeling used means that objects are related parametrically therefore a number of related conditions can be updated by changing only one property. The model can also be used to identify clashes which reduce the cost and the time wasted. The same model can be expanded up to $\mathrm{nD}$ by linking schedules, cost, etc. The BIM model provides easy, faster and more effective information sharing between all participants. It can be used for easy creation of accurate shop drawings, details and project reports. BIM uses object oriented modeling where all elements involved in the building are represented as parametric elements. This representation allows for the creation of large, versatile sets of building components with little effort. One generic element can serve as a template with predefined ranges of characteristics. This parametric data allows the element to be easily reconfigured to suit the unique requirements of implementation in various areas of the model. Depending on the intended BIM use, BIMFORUM.org (www.bimforum.org) presents a detailed classification of the available BIM software packages. After studying the capabilities of available packages it was decided to use Autodesk BIM packages for the following reasons:

1. They are the most comprehensive tools that cover all BIM uses.

2. They are the most used worldwide.

3. There are many extension and add-in applications covering wider scope.

4. Autodesk provides the most comprehensive educational and training tools in addition to continuous on line help.

The following are examples of parametric data and element relationships:

\subsection{Development of BIM CFS Objects}

In the BIM terminology, each building component belongs to a Family. The two basic types of Family in Revit are the System Family and the Component Family. System Families are built into the software and cannot be manipulated by the user. 
Examples of these are "Wall Family", "Floor Family", "Floor Plans", "Sections", and so on. System Families that represent model elements; e.g. Walls and Floors, can "Host" other model element. For example, a Basic Wall Family can host a CFS panelized wall, window, or door. Each family may have one or more types associated with it. While as the basic family cannot be modified by the user, the types associated with it can be modified or even used to create new family types. Component Families include everything that is not a System Family. They can be host-based or free-standing. They can be created or modified from other component families through parametric modeling. The strength of any BIM software lies in the ability to create suitable parametric component families from available family templates to represent a specific building.

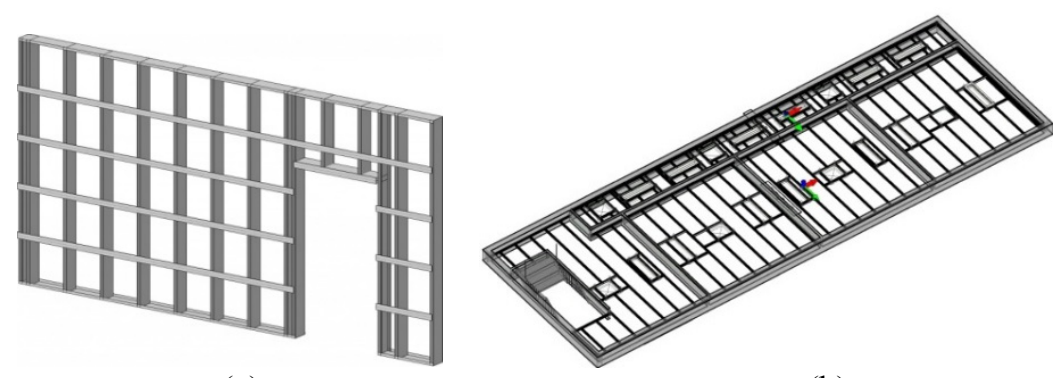

(a)

(b)

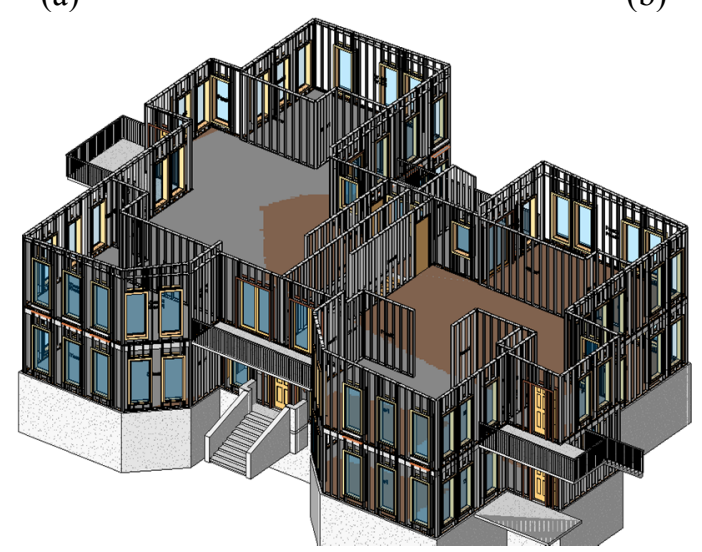

(c)

Figure 3: BIM Parametric Objects. (a) Wall panel object. (b) Floor panel object. (c) Entire building created from wall and floor objects.

The basic procedure for creating parametric component families is as follows:

1. Select a suitable Family Template from the software library.

2. Define the major parameter that control the new family such as size, material, paint, etc.

3. Create and constrain model geometry by defining reference planes and geometry constraints. 


\section{Create Family types if needed.}

This procedure can be applied to create the necessary component families needed to model a typical cold formed steel building, such as:

1. CFS Walls

2. CFS Floors

3. Wall Bracings, and

4. Footings.

An example of the typical procedure used to develop the required parametric objects for CFS Walls is outlined below.

\subsection{Development of parametric objects for CFS walls:}

A CFS wall contains the following components:

a) Vertical studs

b) Horizontal studs (bridging)

c) Top track

d) Bottom track.

The following rules should be considered in creating the parametric component families for the wall:

1. It has to be host-based by a System Family basic wall.

2. The cross sections of all components can vary and shall be selected from the table of optimum cross sections defined in section 5.1 of this report.

3. The material used follow the AISI design specifications [5].

4. Each wall panel is geometrically constrained vertically by the levels of the floor above and floor below and horizontally by its relations with surrounding walls.

5. Each wall may have openings of windows and/or doors.

6. The wall studs are spaced at $600 \mathrm{~mm}$ center to center.

Accordingly, the following procedure can be used to create the parametric objects needed to represent CFS walls:

1. Create parametric objects for each wall component using the templates of the Steel Stud Manufacture Association (SSMA) [6], Figure 4. These templates are available from SSMA and are exported into Revit using the add-in of the software package MWF of StrucSoft Solutions Company (www.strucsoft.com). The templates cover the cross sections used in the USA.

2. Create a Basic Wall Family type to host the CFS wall. Starting with the Revit System Family of "Basic Wall", a new Type is created for the walls used in CFS projects. This wall type is named "Ferrocement Wall" and is created using the Revit basic wall family as follows:

a) The width and height of the new type is equal to the width and height of the CFS wall.

b) The thickness of the new type is equal to the sum of the middle core which will host the CFS wall plus the thickness of the exterior and interior ferrocement boards used to cover the wall from inside and outside. The thickness of the middle core shall be taken equal to the depth of the optimum stud cross section discussed in section 5.1. 
Figure 5 shows the family type created for a CFS wall having a core thickness of $160 \mathrm{~mm}$ and two ferrocement boards $10 \mathrm{~mm}$ on each side.

3. Create parametric object for panel assembly using the cold-formed gauge template (LG) available from MWF as an add-in to Revit. New wall templates are created from the original ones by changing the properties as required by the assembly rules stated above; e.g. stud spacing, wall height, spacing of horizontal bridging, etc., see Figure 6.

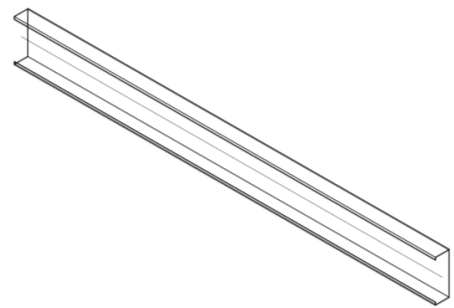

(a)

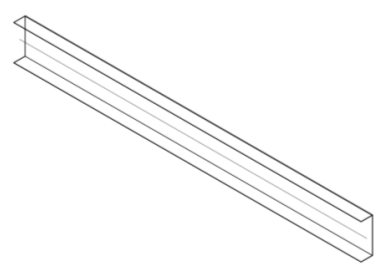

(b)

Figure 4: Parametric objects for CFS wall components. (a) Stud section. (b) Track section.

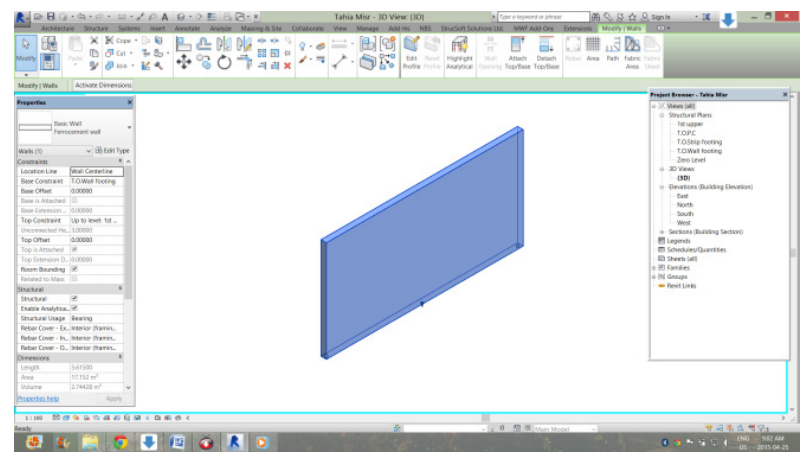

Figure 5: Parametric Family for CFS wall.

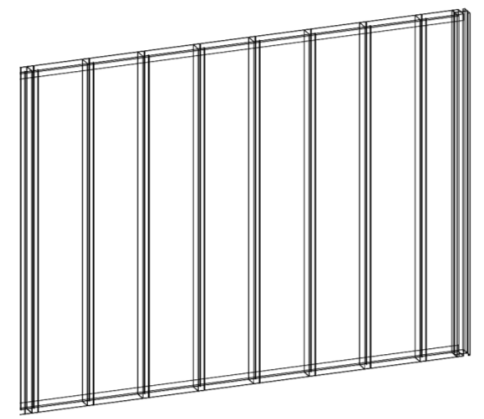

Figure 6: Type Family for CFS Wall. 
Using similar procedures, the parametric families needed for CFS floor panels and strap bracing can be created as shown in Figures 7(a) and 7(b), respectively.

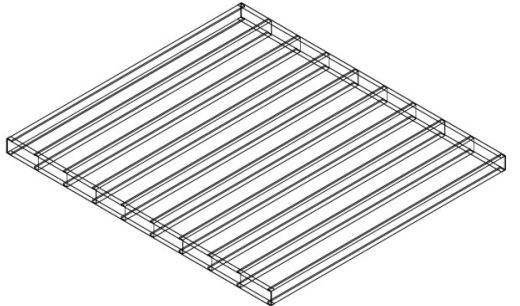

(a)

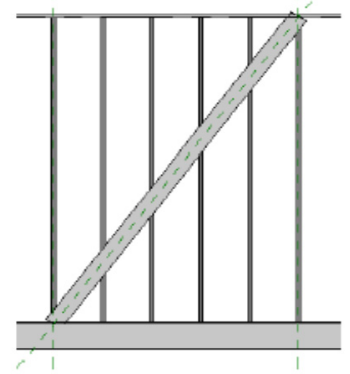

(b)

Figure 7: Floor and braced panels assembly. (a) Floor panel assembly. (b) Braced panel assembly.

\section{BIM use during design phase: structural analysis}

Structural Analysis, in BIM terminology [3], is a process in which analytical modeling software utilizes the BIM design authoring model so to determine the behavior of a given structural system. With the modeling minimum required standards for structural design and analysis are used for optimization. Based on this analysis further development and refinement of the structural design takes place to create effective, efficient, and constructible structural systems. The development of this information is the basis for what will be passed onto the digital fabrication and construction system design phases.

The information integration provided by BIM is utilized during the design stage by using the developed 3D model to perform the structural analysis under different loading conditions. This is usually done by importing the structural layers of the building model into an external analysis package that performs the structural analysis and design of member cross section. For example, if the building basic model is created under Autodesk Revit environment, the structural analysis can be performed using Autodesk Robot Structures. Other package such as STAADPRO or SAP2000 can also be used provided the basic model is imported to them as in Industry Foundation Class (IFC) Format.

Due to the flexibility in manufacturing, cold-formed steel has great advantage to maximize the material efficiency through cross-sectional shapes. Although the sections in the industry [6] hold some advantage in large amount of production, they may not be the most efficient sections to use in the design. Using optimization techniques, the least weight section to satisfy both the strength and serviceability constraints can be found. This approach can be applied on two levels: i) Section optimization and ii) System optimization. 


\subsection{Section optimization}

Cold formed steel sections can be optimized to find the minimum weight needed to satisfy design requirements related to strength and serviceability [5] using the principles of mathematical programming $[7,8]$. Figure 8 shows an example of the variation of the strength to weight ratio versus section aspect ratio for axially loaded members used as stud in CFS walls. The results of these optimization studies can be implemented into the building model during the design stage to insure that the lease weight design is always used.

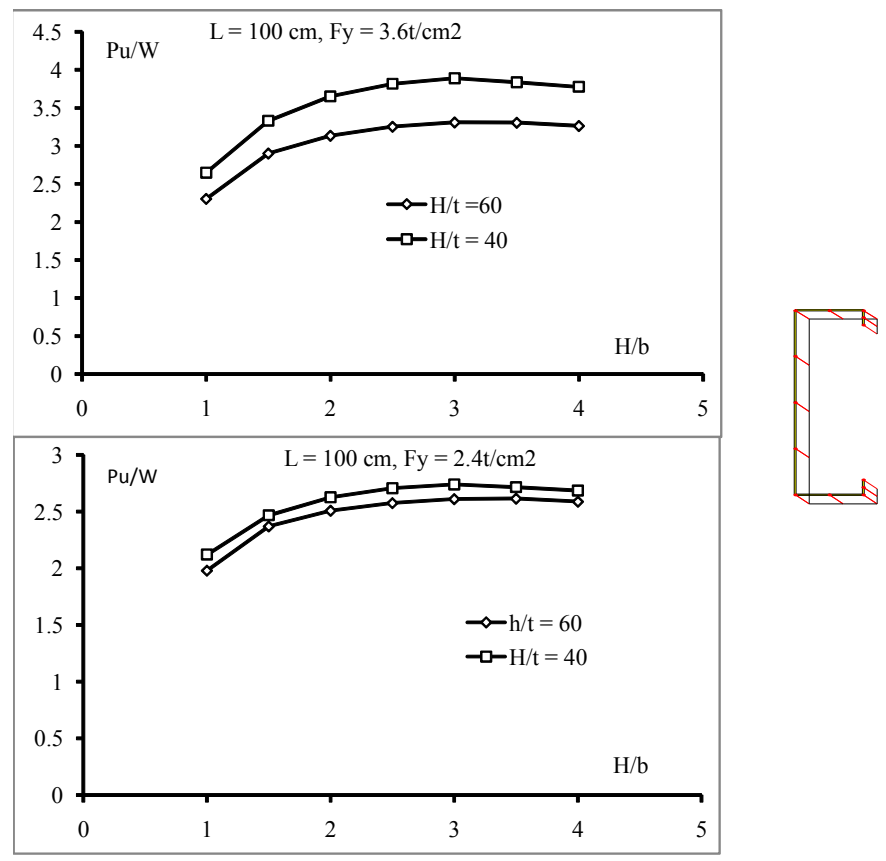

Figure 8: Weight ratio versus section aspect ratio for wall studs.

\subsection{System optimization}

Cold formed steel buildings utilize two distinct structural systems to carry the applied loads:

1. Vertical loads such as gravity and live loads are carried by the load bearing walls consisting of vertical studs spaced at a nominal distance of $600 \mathrm{~mm}$.

2. Lateral loads such as wind or earth quake loads are carried by shear walls distributed in selected locations around the building floor plan.

The configuration of the load bearing walls is more or less pre-determined by the standard spacing of the vertical studs. Optimization of such a system is achieved through the optimization of individual members as shown in section 5.1. On the other hand, several configurations may be used for the shear wall system 
used to resist lateral loads. The three configurations commonly used are shown in Figure 9. The first system uses a strap X-bracing, the second system uses a portal frame truss type bracing and the third system uses two narrow X-bracing bays.

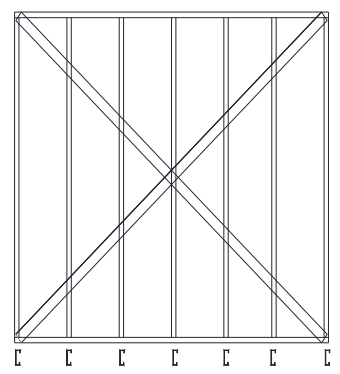

System (1)

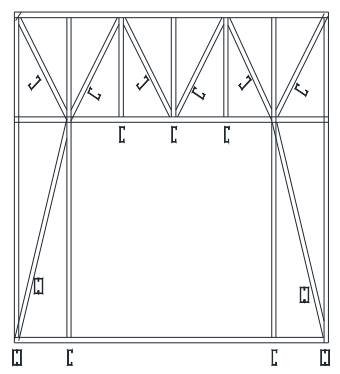

System

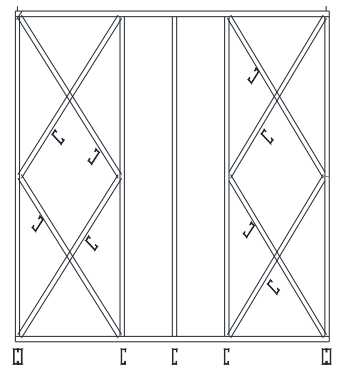

System

Figure 9: Different shear wall systems configurations.

Structural analysis of these systems under different load conditions results in the following conclusions:

1. Based on the resulting member stresses, System (1) has the least factorized weight followed by System (3) the System (2).

2. Based on the resulting horizontal drift, System (2) has the least factorized weight followed by System (1) then System (3).

The choice of one system over another also depends on other operational requirements. For example, System (2) would be most suitable for walls with door or window openings. These conclusions can be programmed into the building model so that the appropriate system is selected in each case.

\section{BIM use during design phase: digital fabrication}

Digital Fabrication, in BIM terminology [3], is a process that uses digitized information to facilitate the fabrication of construction materials or assemblies. Some uses of digital fabrication can be seen in sheet metal fabrication, structural steel fabrication, pipe cutting, prototyping for design intent reviews, etc. It assists in ensuring that the downstream phase of manufacturing has minimum ambiguities and enough information to fabricate with minimal waste. An information model could also be used with suitable technologies to assemble the fabricated parts into the final assembly.

Once the building model has been created using the tools described in the previous sections, it can be used efficiently to explore and evaluate the project's constructability before it is built, visualize construction processes through 4D simulation and clash detection. Furthermore the model can be used to produce the workshop drawings [9] in addition to the required data for Numerical Control Machine fabrication. 


\section{Conclusions}

The paper demonstrated how successful BIM implementation using tools developed for CFS residential buildings can be employed to develop an efficient CFS residential building system. The paper introduces three tools related to BIM uses in Programming, Design Authoring, Structural Analysis, and Digital Fabrication. These tools are:

1. Creation of complex floor plans from few simple modules during the planning phase,

2. Creation of parametric objects for CFS components such as walls, floors and bracings during the design phase,

3. Use of structural optimization principles to achieve the optimum cross section and system design during the design phase.

Once the building model has been created using these tools it can be used efficiently to explore and evaluate the project's constructability before it is built, produce workshop drawings, visualize construction processes through 4D simulation and clash detection in addition to the required data for Numerical Control Machine fabrication.

\section{Acknowledgement}

The research presented in this paper was funded by the Egyptian Science and Technology Development Fund (STDF).

\section{References}

[1] Industrializing the construction site, US Department of Housing and Urban Development (HUD) (2000-2004).

[2] Barret, S. A., et al., Early implementation of building information modeling into a cold-formed steel company, American Journal of Civil Engineering and Architecture, 1(6), pp. 164-173, 2013.

[3] "BIM Project Execution Planning Guide," V2, a BuildingSMART alliance Project Computer Integrated Construction (CIC) Research Program (2010), The Pennsylvania State University, USA.

[4] Modular Prefabricated Residential Construction, University of Washington Report, 2013.

[5] American Iron and Steel Institute, AISI specification for the design of coldformed steel structural members. American Iron and Steel Institute, DC-2001.

[6] Steel Stud Manufacture Association (SSMA), Product technical information, www.ssma.com

[7] Y. S. Tian and T. J. Lu, Minimum weight of cold-formed steel sections under compression, Thin-Walled Structure., 42(4), pp. 515-532, 2004.

[8] T. Tran and L. Li, Global optimization of cold-formed steel channel sections, Thin-Walled Structure., 44(4), pp. 399-406, 2006.

[9] Manrique, J. D, et al., Automated generation of shop drawings in residential construction, Automation in Construction, 55, pp. 15-24, 2015. 